\title{
Low-voltage-area ablation in paroxysmal atrial fibrillation: Extended follow-up results of the VOLCANO trial
}

\author{
Masaharu Masuda ${ }^{1}$, Mitsutoshi Asai ${ }^{1}$, Osamu Iida ${ }^{1}$, Shin Okamoto ${ }^{1}$, Takayuki Ishihara ${ }^{1}$, \\ Kiyonori Nanto ${ }^{1}$, Takashi Kanda ${ }^{1}$, Takuya Tsujimura ${ }^{1}$, Yasuhiro Matsuda ${ }^{1}$, Yosuke Hata ${ }^{1}$, \\ Hiroyuki Uematsu ${ }^{1}$, and Toshiaki Mano ${ }^{1}$ \\ ${ }^{1}$ Kansai Rosai Hospital
}

March 24, 2021

\begin{abstract}
Introduction: The randomized controlled VOLCANO trial demonstrated comparable 1-year rhythm outcomes between patients with and without ablation targeting low-voltage areas (LVAs) in addition to pulmonary vein isolation among paroxysmal atrial fibrillation (AF) patients with LVAs. To compare long-term AF/atrial tachycardia (AT) recurrence rates and types of recurrentatrial-tachyarrhythmia between treatment cohorts during a > 2-year follow-up period. Methods: An extended-follow-up study of 402 patients enrolled in the VOLCANO trial with paroxysmal AF, divided into 4 groups based on the results of voltage mapping: Group A, no LVA $(\mathrm{n}=336)$; group $\mathrm{B}$, LVA ablation $(\mathrm{n}=30)$; group $\mathrm{C}$, LVA presence without ablation ( $\mathrm{n}=32$ ); and group $\mathrm{D}$, incomplete voltage map $(\mathrm{n}=4)$. Results: At $25(23,31)$ months after the initial ablation, AF/AT recurrence rates were $19 \%$ in group A, $57 \%$ in group B, $59 \%$ in group C, and 100\% in group D. Recurrence rates were higher in patients with LVAs than those without (group A vs. $\mathrm{B}+\mathrm{C}, \mathrm{p}<0.0001$ ), and were comparable between those with and without LVA ablation (group B vs. C, $\mathrm{p}=0.83$ ). Among patients who underwent repeat ablation, ATs were more frequently observed in patients with LVAs (Group B+C, $50 \%$ vs. A, 14\%, p<0.0001). In addition, LVA ablation increased the incidence of AT development (group B, $71 \%$ vs. C, $32 \%, \mathrm{p}<0.0001$ ), especially biatrial tachycardia ( $20 \%$ vs. $0 \%, \mathrm{p}=0.01$ ). Conclusion: Patients with LVAs demonstrated poor long-term rhythm outcomes irrespective of LVA ablation. ATs were frequently observed in patients with LVAs, and LVA ablation might exacerbate iatrogenic ATs.
\end{abstract}

\section{Introduction}

The presence of left atrial low-voltage areas (LVAs) has been strongly associated with AF recurrence after PVI even in patients with paroxysmal AF ${ }^{1-3}$ Several observational studies have reported the possible efficacy of ablation targeting LVAs. ${ }^{1,4}$

VOLCANO was a randomized controlled trial that compared 1-year AF recurrence rates between following ablation strategies: PVI alone for patients without LVAs, PVI plus LVA ablation for those with LVAs, and PVI alone for those with LVAs. ${ }^{5}$ Results showed that poorer rhythm outcomes in patients with LVAs than those without. In addition, comparable AF recurrence rates were observed between patients with and without LVA ablation, suggesting that LVA ablation in addition to PVI had no beneficial impact on 1-year rhythm outcomes in paroxysmal AF patients. However, the VOLCANO trial had a relatively short follow-up period, which limited its clinical implications.

Here, to overcome this limitation, we conducted an extended follow-up study of the VOLCANO trial which compared rhythm outcomes over more than 2 years of follow-up, and types of recurrent-atrialtachyarrhythmias between the treatment cohorts.

\section{Methods}




\section{Study design}

This study was a prospective observational study which included patients enrolled in the randomized controlled VOLCANO trial. This study complied with the Declaration of Helsinki. Written informed consent for participation in the study was obtained from all patients, and the protocol was approved by our institutional review board.

\section{Patients}

The original VOLCANO trial included 402 patients with paroxysmal AF who underwent AF ablation (Figure 1). Patients were divided into the 4 groups based on the results of voltage mapping. Group A consisted of patients without LVA on the voltage map after PVI $(\mathrm{n}=336)$. Patients with left atrial LVAs were randomly allocated in a 1:1 fashion to group B, which underwent LVA ablation $(\mathrm{n}=30)$, or group C, without LVA ablation $(\mathrm{n}=32)$. Group $\mathrm{D}$ included patients in whom voltage mapping was not completed due to unstable cardiac rhythm $(\mathrm{n}=4)$.

\section{Follow up}

Patients in the VOLCANO trial were followed for 12 months. After this protocol period, follow up was continued for 1 years or more ([?] 2 years after the index ablation procedure), usually every 3 months. Routine electrocardiograms (ECGs) were conducted at each outpatient visit. When patients experienced symptoms suggestive of an arrhythmia, surface ECG, ambulatory ECG, and/or cardiac event recording were also conducted at the discretion of the attending physician. AF or atrial tachycardia (AT) recurrence was defined as the occurrence of one of the following events: (1) AF/AT indicated on a routine or symptomtriggered ECG during an outpatient visit; or (2) AF/AT of at least 30-s duration on ambulatory ECG monitoring. AF/AT episodes during the 3 months after the initial or repeat ablation were not included in the recurrence events (blanking period). No AADs were prescribed after the ablation procedure unless $\mathrm{AF} / \mathrm{AT}$ recurrence was observed.

Repeat ablation procedure

Repeat ablation was recommended for recurrent $\mathrm{AF} / \mathrm{AT}$ that developed $>3$ months after the prior ablation.

Electrophysiological studies and catheter ablation were performed under intravenous sedation with dexmedetomidine. A 6-Fr decapolar electrode was inserted into the coronary sinus while a second 6-Fr decapolar electrode was placed in the right atrium. Following transseptal puncture at the fossa ovalis, two long sheaths were introduced into the left atrium. The operators performed mapping and ablation guided by an electroanatomical mapping system (Rhythmia ${ }^{\circledR}$, Boston Scientific, Marlborough [Cambridge] MA, USA or Carto3 ${ }^{(\mathrm{r})}$, Biosense Webster, Diamond Bar CA, USA). When Rhythmia was used, a 64-pole mini-basket catheter (Orion(r), Boston Scientific) and an open-irrigated ablation catheter with a 3.5-mm tip (Thermocool Celsius $^{(\mathrm{r})}$, Biosense Webster) were used. When CARTO 3 was used, a 20-pole multielectrode mapping catheter arranged in 5 soft radiating spines $\left(\right.$ Pentaray $^{(\mathrm{r})}$, Biosense Webster) and an open-irrigated ablation catheter with a 3.5-mm tip (Thermocool SmartTouch ${ }^{(\mathrm{r})}$, Biosense Webster) were used.

Prior to the ablation procedure, we examined the electrical conduction between each PV and the left atrium. If the conduction indicated reconnection, radiofrequency energy was applied at the estimated gap sites. After re-isolation of reconnected PVs, atrial burst pacing (cycle length 200 to $300 \mathrm{ppm}$ for $5 \mathrm{sec}$ ) was performed, followed by a high-dose isoproterenol provocation test (infusion of 5,10 , and $20 \mu \mathrm{g} / \mathrm{min}$ isoproterenol for 2 min each) to induce AF or AT. AF-triggering ectopies or frequent ectopies originating from the superior vena cava were eliminated by circumferential superior vena cava isolation. Non-PV AF-triggering ectopies were ablated at the earliest activation site. Spontaneously developing or induced AT was also mapped using the electroanatomical mapping system. Focal ablation targeting the earliest activation site for a centrifugal AT or ablation crossing the reentrant circuit for a macro-reentrant AT was performed.

Empirical ablations such as superior vena cava isolation, and linear ablations of the roof, bottom, lateral mitral isthmus and cavo-tricuspid isthmus were additionally conducted at the discretion of the attending 
operators. Ablation targeting LVAs, defined as areas with a low bipolar-peak-to-peak voltage $<0.50 \mathrm{mV}$, was also allowed, irrespective of allocated group.

\section{Statistical analysis}

Continuous data are expressed as the mean \pm standard deviation or median (interquartile range). Categorical data are presented as absolute values and percentages. Tests for significance were conducted using the unpaired $t$-test, repeated measures analysis of variance, or a nonparametric test (Mann-Whiney $U$-test) for continuous variables and the chi-squared test or Fisher's exact test for categorical variables. AF/AT recurrence rates were calculated using the Kaplan-Meier method. Survival curves between the groups were compared using the 2-sided Mantel-Haenszel (log-rank) test. A p-value $<0.05$ was considered statistically significant. Clinical factors associated with AF recurrence were determined by univariate and multivariate Cox proportional hazards models. Variables with a p-value [?] 0.05 in the univariate models were included in the multivariate analysis. The analyses were exploratory and no adjustments were made. All analyses were performed using commercial software (SPSS version $25.0^{(\mathrm{r})}$, SPSS, Inc., Chicago IL, USA).

\section{Results}

\section{Patients}

Baseline characteristics were presented previously. ${ }^{5}$ In brief, age was $67.8+-11.6$ in group A, $75.3+-7.2$ in group B, $74.7+-8.0$ in group C, and $74.0+-6.0$ years old in group D. Females were $39 \%, 70 \%, 72 \%$, and $0 \%$, respectively. $\mathrm{CHA}_{2} \mathrm{DS}_{2}$-VASc score was $2.4+-1.4,3.6+-1.2,3.3+-1.3$, and $3.3+-1.0$, and left atrial diameter was $37+-6,40+-6,38+-5$, and $43+-6 \mathrm{~mm}$, respectively.

Patient flow is shown in Figure 1. Patients enrolled in the VOLCANO trial were followed for $25(23,31)$ months after the initial ablation. Among 402 patients in the trial, 104 (25.8\%) patients developed AF/AT recurrence (Table 1). Ten (2.5\%) patients died during the follow-up period, of whom 6 developed AF/AT recurrence before death. By group, 6 died in group A, 1 in group B, 2 in group C, 1 in group D. Cause of death was heart failure in 3 patients, stroke in 2, cancer in 2, and gastrointestinal perforation, trauma, and unknown in 1 patient each.

\section{Recurrent $A F / A T$}

$\mathrm{AF} / \mathrm{AT}$ recurrence was observed in 104 (25.9\%) patients after the initial ablation, with higher recurrence rates in patients with LVAs (group B+C) than in those without (group A, Figure 2A and Table 1). No difference was observed between group B and C. All patients developed AF/AT recurrence in group D. Multivariate analyses of patients having complete voltage maps revealed that female, large left atrial diameter, and LVA presence were independently associated with AF/AT recurrence (Table 2). Among patients with LVAs, large left atrial diameter was the only associated factor (Table 3).

Transformation from paroxysmal AF to persistent AF was more frequently observed in patients with LVAs (group B $+\mathrm{C}$ ) than in those without (group A, Figure 3A). In addition, patients with LVAs (group B $+\mathrm{C}$ ) more frequently experienced late $\mathrm{AF} / \mathrm{AT}$ recurrence, defined as recurrence at $>6$ months after the last ablation, than those without (group A, Figure 3B).

\section{Repeat ablation}

Repeat ablation was more frequent in patients with LVAs (group B + C) than those without (group A, Table 1). Median duration between the initial and second ablation sessions was $10(8,16)$ months.

In the second ablation procedure, proportions of complete PV isolation, defined as isolation of all 4 pulmonary veins from the left atrium, were comparable between the groups, namely $49 \%$ (23 of 46) patients in group A, $36 \%$ ( 5 of 14) in group B, 33\% (3 of 9) in group C, and 50\% (1 of 2, p = 0.73) in group D. All reconnected PVs were successfully isolated.

During the repeat ablation procedure, a total of 31 regular ATs could provide a complete activation map, developed spontaneously or by atrial burst pacing, with higher frequency in patients with LVAs (group B $+\mathrm{C}$ ) 
than in those without LVA (group A, Figure 4A). Patients with LVA ablation (group B) experienced regular ATs more frequently than those without (group C). AT circuits determined by electroanatomical mapping are demonstrated in Figure 4B. Ablation successfully eliminated 29 of 31 (93.5\%) ATs. The remaining 2 ATs with failed ablation were biatrial tachycardias observed in group B.

Ablation lesions throughout all ablation procedures are shown in Table 1. Patients with LVAs (group B $+\mathrm{C}$ ) more frequently underwent extra PV ablation than those without (group A). Patients in group B more often received left atrial roof, bottom and anterior-septal linear ablations than those in group C. In contrast, non-PV AF trigger ablation was more frequent in group $\mathrm{C}$ than in group $\mathrm{B}$.

\section{Biatrial tachycardia}

Six of 31 regular ATs had reentrant circuits which included both the right and left atria (biatrial tachycardia). Notably, all 6 of these biatrial tachycardias were observed in group B, and no patients in other groups developed biatrial tachycardia. The reentrant circuit consisted of the mitral annulus and right atrial septum in all biatrial tachycardias.

Clinical background, ablation procedures, and ablation outcomes of each patient with biatrial tachycardia are shown in the Supplementary Table. Comparisons of anatomical and electrophysiological properties between patients with and without biatrial AT in group B are shown in Table 4. Patients with biatrial tachycardia had larger anterior and/or septal LVAs, and underwent anterior and/or septal linear ablations.

Ablation targeting breakout points into the left and/or right atria successfully eliminated biatrial tachycardia in 4 of $6(66.7 \%)$ patients. In the remaining 2 patients with failed ablation at left and right atrial breakout points, lateral mitral isthmus linear ablation was performed in 1 patient, but block line could not be achieved. The other patient had conduction disturbance across the septal to anterior region due to an ablation scar, and did not undergo lateral mitral isthmus ablation in consideration of electrical isolation of the left atrial appendage.

Successful AT elimination rate was significantly lower for biatrial tachycardias than for the other ATs (4 of $6[66.7 \%]$ vs. 25 of 25 [100\%] ATs, p = 0.010).

\section{Rhythm outcomes after multiple ablations}

After a mean of $1.2+-0.5$ ablations, AF/AT recurrence developed in 49 (12.2\%) patients. AF/AT recurrence rates after multiple ablations in treatment cohorts are compared in Figure 2B. Patients with LVAs at the initial procedure (group $\mathrm{B}+\mathrm{C}$ ) demonstrated more frequent AF/AT recurrence even after multiple ablations. $\mathrm{AF} / \mathrm{AT}$ recurrence rates were comparable between those with (group B) and without LVA ablation (group C).

At the time of the final out-patient clinic, 19 (4.7\%) patients were taking anti-arrhythmic drugs (Table 1). The proportion of patients with sinus rhythm on ECG at that time was significantly higher in patients without LVA (group A) than in those with (group B+C), although there was no difference between groups $\mathrm{B}$ and $\mathrm{C}$.

\section{Discussion}

This observational study followed up patients enrolled in the randomized controlled VOLCANO trial. Four main findings were recognized: (1) Patients with LVAs at the initial ablation experienced more frequent longterm ( $>2$ years) AF/AT recurrence and loss of sinus rhythm on final follow-up ECG than those without; (2) an ablation strategy targeting LVA failed to show a beneficial impact on long-term AF/AT recurrence after single and multiple ablations; (3) spontaneously developed or pacing-induced regular ATs were more often observed in patients with LVAs than in those without; and (4) LVA ablation increased AT development at repeat ablation, especially biatrial tachycardia after anterior-septal LVA ablation.

Poor rhythm outcomes in patients with LVAs 
Patients with LVAs demonstrated a higher AF/AT recurrence rate during the long-term follow-up period than those without LVAs, even after multiple ablations. This in turn suggests that durable PVI, and ablation targeting non-PV AF triggers and induced regular ATs does not sufficiently suppress arrhythmogenic substrate in patients with LVAs. Furthermore, transformation from the paroxysmal to persistent form of $\mathrm{AF}$ and late recurrence of $\mathrm{AF} / \mathrm{AT}$ were more often observed in patients with LVAs. These findings suggest that atrial arrhythmogenic substrate progresses after the ablation procedure. The generation of LVAs in paroxysmal AF is relatively dependent on upstream factors causing atrial remodeling, such as aging, female gender, and elevated atrial pressure rather than AF burden. ${ }^{6-8}$ These upstream factors would likely to continue to remodel the atrium even after ablation.

In addition, ablation targeting LVAs did not reduce AF/AT recurrence. Two hypotheses may explain why LVA ablation failed to suppress AF episodes. First, not all arrhythmogenic substrate is included within LVAs, although LVAs themselves indicate the presence of extra-PV arrhythmogenic substrate. Several studies have suggested that preserved-voltage areas may also serve as arrhythmogenic substrate. ${ }^{9,10}$ Second, arrhythmogenic substrate might progress even after ablation, as mentioned above, and ablation of LVAs at the time of the ablation procedure does not mean eternal LVA modification.

Regular AT in patient with LVAs

Patients with LVAs more frequently developed spontaneous or pacing-induced regular ATs than those without LVAs. In addition, among patients with LVAs, LVA ablation increased AT incidence. The association between advanced atrial remodeling and extensive atrial ablation with AT development is consistent with previous reports. Among these, ATs developed in 5\% to $40 \%$ of patients who underwent AF ablation, and the incidence became higher in patients with longer AF duration or larger left atrium; ${ }^{11-13}$ while extensive ablation targeting complex fractionated electrograms resulted in frequent AT development. ${ }^{14}$

The electrophysiological mechanism of the association between LVA presence and LVA ablation with AT development might be explained as follows. LVA is reported to include a slow conduction zone and conduction block, ${ }^{15}$ and could act as an arrhythmogenic substrate of reentrant ATs. Although ablation targeting LVAs changes diseased conduction areas into scar areas with no electrical conduction, LVA ablation near anatomical obstacles such as the valvular annulus may unintentionally create an iatrogenic slow conduction isthmus. Furthermore, linear ablation to isolate LVAs could create conduction gaps due to incomplete linear lesions.

\section{Biatrial tachycardia}

A previous study reported that biatrial tachycardia is more likely to develop in patients with an obstacle to conduction in the left atrial septum. ${ }^{16,17}$ In this study, all cases of biatrial tachycardia developed in patients with broad anterior-septal LVA ablation. In contrast, biatrial tachycardia was not observed in patients without anterior-septal ablation, even in patients with broad LVA at the anterior-septal lesion. This suggests that conduction block by ablation scar rather than conduction slowing due to diseased myocardium provides the substrate for biatrial tachycardia.

An ablation target of biatrial tachycardia is the left or right atrial conduction breakout points. ${ }^{14}$ However, it is sometimes difficult to eliminate reentrant circuits, possibly due to broad inter-atrial conduction. In this study, ablation did not eliminate biatrial tachycardia in 2 of 6 patients (Supplementary Table). Lateral mitral isthmus ablation can be an alternative ablation target of biatrial tachycardia, ${ }^{15}$ but requires careful consideration of electrical conduction disturbance to the left atrial appendage.

\section{Limitations}

Several limitations of this study warrant mention. First, the definition of low-voltage areas (areas with a voltage $<0.5 \mathrm{mV}$ covering $5.0 \mathrm{~cm}^{2}$ of the left atrial surface) was somewhat arbitrary. Second, some patients in group $\mathrm{A}$ and $\mathrm{C}$ underwent LVA ablation, because there was no protocol strategy for repeat ablation. Third, AF recurrence after discharge was quantified on the basis of patient symptoms, giving rise to the possibility that asymptomatic episodes of AF might have been missed. Fourth, some patients died or were lost to follow-up before end of the 2-year follow-up period after initial ablation. Finally, the small sample size 
might have biased the patient characteristics and limited the statistical accuracy of our results. Multicenter randomized controlled trials in sufficient numbers of patients are warranted.

\section{Conclusions}

Patients with LVAs demonstrated poor long-term rhythm outcomes irrespective of LVA ablation. ATs were frequently observed in patients with LVAs, and LVA ablation might exacerbate iatrogenic AT.

\section{Author contributions}

Concept, Design, Drafting the manuscript: M. Masuda

Data collection and Revising the manuscript: M. Asai, O. Iida, S. Okamoto, T. Ishihara, K. Nanto, T. Kanda, T. Tsujimura, Y. Matsuda, Y. Hata, H. Uematsu

Final approval of the manuscript: T. Mano

\section{References}

1. Rolf S, Kircher S, Arya A, Eitel C, Sommer P, Richter S, Gaspar T, Bollmann A, Altmann D, Piedra $\mathrm{C}$, et al. Tailored atrial substrate modification based on low-voltage areas in catheter ablation of atrial fibrillation. Circ Arrhythm Electrophysiol 2014;7:825-833.

2. Masuda M, Fujita M, Iida O, Okamoto S, Ishihara T, Nanto K, Kanda T, Tsujimura T, Matsuda Y, Okuno S, et al. Left atrial low-voltage areas predict atrial fibrillation recurrence after catheter ablation in patients with paroxysmal atrial fibrillation. Int J Cardiol 2018;257:97-101.

3. Vlachos K, Efremidis M, Letsas KP, Bazoukis G, Martin R, Kalafateli M, Lioni L, Georgopoulos $\mathrm{S}$, Saplaouras A, Efremidis T, et al. Low-voltage areas detected by high-density electroanatomical mapping predict recurrence after ablation for paroxysmal atrial fibrillation. J Cardiovasc Electrophysiol 2017;28:1393-1402.

4. Yamaguchi T, Tsuchiya T, Nakahara S, Fukui A, Nagamoto Y, Murotani K, Eshima K, Takahashi N. Efficacy of left atrial voltage-based catheter ablation of persistent atrial fibrillation. J Cardiovasc Electrophysiol 2016;27:1055-1063.

5. Masuda M, Asai M, Iida O, Okamoto S, Ishihara T, Nanto K, Kanda T, Tsujimura T, Matsuda Y, Okuno S, Hata Y, Mano T. Additional low-voltage-area ablation in patients with paroxysmal atrial fibrillation: results of the randomized controlled VOLCANO trial. J Am Heart Assoc 2020;9:e015927.

Masuda M, Fujita M, Iida O, Okamoto S, Ishihara T, Nanto K, et al. Influence of underlying substrate on atrial tachyarrhythmias after pulmonary vein isolation. Heart Rhythm 2016;13:870-878.

Kosiuk J, Dinov B, Kornej J, Acou WJ, Schonbauer R, Fiedler L, et al. Prospective, multicenter validation of a clinical risk score for left atrial arrhythmogenic substrate based on voltage analysis: DR-FLASH score. Heart Rhythm 2015;12:2207-2212.

Park J, Joung B, Uhm JS, Young Shim C, Hwang C, Hyoung et al. High left atrial pressures are associated with advanced electroanatomical remodeling of left atrium and independent predictors for clinical recurrence of atrial fibrillation after catheter ablation. Heart Rhythm 2014;11:953-960.

Yagishita A, Sparano D, Cakulev I, Gimbel JR, Phelan T, Mustafa H, De Oliveira S, Mackall J, Arruda M. Identification and electrophysiological characterization of early left atrial structural remodeling as a predictor for atrial fibrillation recurrence after pulmonary vein isolation. J Cardiovasc Electrophysiol 2017;28:642-650.

Kurata N, Masuda M, Kanda T, Asai M, Iida O, Okamoto S, Ishihara T, Nanto K, Tsujimura T, Matsuda Y, Hata Y, Mano T. Slow whole left atrial conduction velocity after pulmonary vein isolation predicts atrial fibrillation recurrence. J Cardiovasc Electrophysiol 2020;31:1942-1949.

Wasmer K, Monnig G, Bittner A, Dechering D, Zellerhoff S, Milberg P, Kobe J, Eckardt L. Incidence, characteristics, and outcome of left atrial tachycardias after circumferential antral ablation of atrial fibrillation. Heart Rhythm 2012;9:1660-6. 
Deisenhofer I, Estner H, Zrenner B, Schreieck J, Weyerbrock S, Hessling G, Scharf K, Karch MR, Schmitt C. Left atrial tachycardia after circumferential pulmonary vein ablation for atrial fibrillation: incidence, electrophysiological characteristics, and results of radiofrequency ablation. Europace. 2006;8:573-82.

Chugh A, Oral H, Lemola K, Hall B, Cheung P, Good E, Tamirisa K, Han J, Bogun F, Pelosi F Jr, Morady F. Prevalence, mechanisms, and clinical significance of macroreentrant atrial tachycardia during and following left atrial ablation for atrial fibrillation. Heart Rhythm 2005;2:464-71.

Oral H, Chugh A, Good E, Wimmer A, Dey S, Gadeela N, Sankaran S, Crawford T, Sarrazin JF, Kuhne M, Chalfoun N, Wells D, Frederick M, Fortino J, Benloucif-Moore S, Jongnarangsin K, Pelosi F Jr, Bogun F, Morady F. Radiofrequency catheter ablation of chronic atrial fibrillation guided by complex electrograms. Circulation. 2007;115:2606-12.

Miyamoto K, Tsuchiya T, Narita S, Yamaguchi T, Nagamoto Y, Ando S, Hayashida K, Tanioka Y, Takahashi N. Bipolar electrogram amplitudes in the left atrium are related to local conduction velocity in patients with atrial fibrillation. Europace 2009; 11: 1597-1605.

Mikhaylov EN, Mitrofanova LB, Vander MA, Tatarskiy RB, Kamenev AV, Abramov ML, Szili-Torok T, Lebedev DS. Biatrial tachycardia following linear anterior wall ablation for the perimitral reentry: incidence and electrophysiological evaluations.J Cardiovasc Electrophysiol. 2015; 26:28-35. doi: 10.1111/jce.12543.

Kitamura T, Martin R, Denis A, Takigawa M, Duparc A, Rollin A, Frontera A, Thompson N, Massoullie G, Cheniti G, Wolf M, Vlachos K, Martin C, Jefairi N, Duchateau J, Klotz N, Pambrun T, Sacher F, Cochet H, Hocini M, Haissaguerre M, Maury P, Jais P, Derval N. Characteristics of single-loop macroreentrant biatrial tachycardia diagnosed by ultra-high-resolution mapping system. Circ Arrhythm Electrophysiol 2018;11:e005558.

Table 1. Outcomes and repeat ablation procedures

\begin{tabular}{|c|c|c|c|c|c|c|}
\hline & Group $A$ & Group B & Group $C$ & Group D & $p$ & $p$ \\
\hline & $n=336$ & $n=30$ & $n=32$ & $n=4$ & $\begin{array}{l}\text { Group A vs. } \\
B+C\end{array}$ & Group B vs. $C$ \\
\hline \multicolumn{7}{|l|}{$\begin{array}{l}\mathrm{AF} / \mathrm{AT} \\
\text { recurrence }\end{array}$} \\
\hline $\begin{array}{l}\text { After the } \\
\text { initial } \\
\text { ablation }\end{array}$ & $64(19)$ & $17(57)$ & $19(59)$ & $4(100)$ & $<0.0001$ & 0.83 \\
\hline \multicolumn{7}{|l|}{$\begin{array}{l}\text { Cardiac } \\
\text { rhythm at } \\
\text { final follow } \\
\text { up }\end{array}$} \\
\hline $\begin{array}{l}\text { Antiarrhythmic } \\
\text { drugs }\end{array}$ & $16(5)$ & $4(13)$ & $3(9)$ & $2(50)$ & 0.043 & 0.70 \\
\hline $\begin{array}{l}\text { Sinus } \\
\text { rhythm or } \\
\text { paced } \\
\text { rhythm } \\
\text { Death }\end{array}$ & 332 (99) & $25(83)$ & $29(91)$ & $1(25)$ & $<0.0001$ & 0.47 \\
\hline $\begin{array}{l}\text { All-cause } \\
\text { death }\end{array}$ & $6(2)$ & $1(3)$ & $2(6)$ & $1(25)$ & 0.15 & 1.00 \\
\hline $\begin{array}{l}\text { Cardiovascular } \\
\text { death }\end{array}$ & $2(1)$ & $1(3)$ & $1(3)$ & $1(25)$ & 0.12 & 1.00 \\
\hline
\end{tabular}




\begin{tabular}{|c|c|c|c|c|c|c|}
\hline & Group A & Group B & Group $C$ & Group D & $p$ & $p$ \\
\hline \multicolumn{7}{|l|}{$\begin{array}{l}\text { Repeat } \\
\text { ablation }\end{array}$} \\
\hline $\begin{array}{l}\text { [?] } 1 \text { repeat } \\
\text { ablation }\end{array}$ & $46(14)$ & $14(47)$ & $9(28)$ & $2(50)$ & $<0.0001$ & 0.13 \\
\hline $\begin{array}{l}\text { Number of } \\
\text { ablation } \\
\text { sessions }\end{array}$ & $1.2 \pm 0.4$ & $1.5 \pm 0.6$ & $1.4 \pm 0.8$ & $1.5 \pm 0.6$ & 0.001 & 0.47 \\
\hline $\begin{array}{l}\text { Ablation } \\
\text { procedures } \\
\text { through- } \\
\text { out all } \\
\text { ablation } \\
\text { sessions }\end{array}$ & & & & & & \\
\hline $\begin{array}{l}\text { LVA } \\
\text { ablation }\end{array}$ & $7(2)$ & $30(100)$ & $5(16)$ & $0(0)$ & $<0.0001$ & $<0.0001$ \\
\hline $\begin{array}{l}\text { Ablation for } \\
\text { ATs except } \\
\text { for common } \\
\text { flutter }\end{array}$ & $8(2)$ & $11(37)$ & $5(16)$ & $0(0)$ & $<0.0001$ & 0.058 \\
\hline $\begin{array}{l}\text { Ablation for } \\
\text { non- } P V, \\
\text { non- } S V C \\
\text { trigger }\end{array}$ & $22(7)$ & $2(7)$ & $9(28)$ & $3(75)$ & 0.003 & 0.044 \\
\hline $\begin{array}{l}S V C \\
\text { isolation }\end{array}$ & 36 (11) & $7(23)$ & $6(19)$ & $2(50)$ & 0.024 & 0.66 \\
\hline Roof line & $11(3)$ & $17(57)$ & $3(9)$ & $2(50)$ & $<0.0001$ & $<0.0001$ \\
\hline Bottom line & $7(2)$ & $11(37)$ & $3(9)$ & $2(50)$ & $<0.0001$ & 0.015 \\
\hline $\begin{array}{l}\text { Anterior- } \\
\text { septal mitral } \\
\text { line }\end{array}$ & $1(0)$ & $11(37)$ & $1(3)$ & $0(0)$ & $<0.0001$ & 0.001 \\
\hline $\begin{array}{l}\text { Lateral } \\
\text { mitral line }\end{array}$ & $0(0)$ & $4(13)$ & $1(3)$ & $0(0)$ & $<0.0001$ & 0.19 \\
\hline $\begin{array}{l}\text { Cavo- } \\
\text { tricuspid } \\
\text { isthmus line }\end{array}$ & $55(16)$ & $14(47)$ & $12(38)$ & $3(75)$ & $<0.0001$ & 0.47 \\
\hline
\end{tabular}

AF, atrial fibrillation; AT, atrial tachycardia; LVA, low-voltage area; SVC, superior vena cava.

Table 2. Factors associated with AF/AT recurrence* among patients with a complete voltage map (Group A+B+C).

\begin{tabular}{|c|c|c|c|c|c|c|c|c|}
\hline & Recurrence & Recurrence & Univariate & Univariate & Univariate & \multicolumn{3}{|c|}{ Multivariate Multivariate Multiv } \\
\hline & $\begin{array}{l}\text { With } n= \\
100\end{array}$ & $\begin{array}{l}\text { Without n } \\
=298\end{array}$ & $H R$ & $95 \% C I$ & $P$ & $H R$ & $95 \% C I$ & $p$ \\
\hline $\begin{array}{l}\text { Age, } \\
\text { years }\end{array}$ & $70.4 \pm 10.3$ & $68.5 \pm 11.7$ & 1.01 & $\begin{array}{l}0.99- \\
1.03\end{array}$ & 0.18 & & & \\
\hline $\begin{array}{l}\text { Female, } \\
\text { n (\%) }\end{array}$ & $62(62)$ & $113(38)$ & 2.28 & $\begin{array}{l}1.53- \\
3.42\end{array}$ & $<0.0001$ & 1.88 & $\begin{array}{l}1.24- \\
2.86\end{array}$ & 0.003 \\
\hline
\end{tabular}




\begin{tabular}{|c|c|c|c|c|c|c|c|c|}
\hline & Recurrence & Recurrence & Univariate & Univariate & Univariate & \multicolumn{3}{|c|}{ Multivariate Multivariate Multiv } \\
\hline $\begin{array}{l}\text { Body } \\
\text { mass } \\
\text { index }\end{array}$ & $23.1 \pm 3.8$ & $23.6 \pm 3.8$ & 0.97 & $\begin{array}{l}0.91- \\
1.04\end{array}$ & 0.40 & & & \\
\hline $\begin{array}{l}\text { AF } \\
\text { period, } \\
\text { months }\end{array}$ & $6(3,16)$ & $7(3,18)$ & 0.998 & $\begin{array}{l}0.993- \\
1.003\end{array}$ & 0.46 & & & \\
\hline $\begin{array}{l}\text { Heart } \\
\text { failure, } \\
\text { n }(\%)\end{array}$ & $14(14)$ & $27(9)$ & 1.51 & $\begin{array}{l}0.86- \\
2.66\end{array}$ & 0.15 & & & \\
\hline $\begin{array}{l}\mathrm{CHA}_{2} \mathrm{DS}_{2-} \mathrm{V} \\
\text { score }\end{array}$ & A.Se 1.4 & $2.5 \pm 1.4$ & 1.14 & $\begin{array}{l}0.99- \\
1.30\end{array}$ & 0.065 & & & \\
\hline $\begin{array}{l}\text { Estimated } \\
\text { GFR, } \\
\mathrm{pg} / \mathrm{ml}\end{array}$ & $58 \pm 17$ & $59 \pm 20$ & 0.996 & $\begin{array}{l}0.99- \\
1.01\end{array}$ & 0.44 & & & \\
\hline $\begin{array}{l}\text { Left } \\
\text { atrial } \\
\text { diame- } \\
\text { ter, } \\
\text { mm }\end{array}$ & $38.9 \pm 6.0$ & $37.4 \pm 6.1$ & 1.04 & $\begin{array}{l}1.004- \\
1.07\end{array}$ & 0.029 & 1.04 & $\begin{array}{l}1.0041- \\
1.07\end{array}$ & 0.029 \\
\hline $\begin{array}{l}\text { LVA } \\
\text { pres- } \\
\text { ence, } \mathbf{n} \\
(\%)\end{array}$ & $36(36)$ & $26(9)$ & 4.00 & $\begin{array}{l}2.65- \\
6.01\end{array}$ & $<0.0001$ & 3.29 & $\begin{array}{l}2.15- \\
5.02\end{array}$ & $<0.000$ \\
\hline
\end{tabular}

Factors with $\mathrm{p}<0.05$ in the univariate analysis were incorporated into the multivariate analysis. *AF recurrence indicates recurrence of both atrial fibrillation and atrial tachycardia. HR, hazard ratio; CI, confidence interval, AF, atrial fibrillation; GFR, glomerular filtration rate; LVA, low-voltage area.

Table 3. Factors associated with AF/AT recurrence* among patients with LVA (Group B+C).

\begin{tabular}{|c|c|c|c|c|c|c|c|c|}
\hline & Recurrence & Recurrence & Univariate & Univariate & Univariate & \multicolumn{3}{|c|}{ Multivariate Multivariate Multiv } \\
\hline & $\begin{array}{l}\text { With } n= \\
36\end{array}$ & $\begin{array}{l}\text { Without n } \\
=26\end{array}$ & $H R$ & $95 \% C I$ & $p$ & \multirow[t]{5}{*}{$H R$} & \multirow[t]{5}{*}{$95 \% C I$} & \multirow[t]{5}{*}{$p$} \\
\hline $\begin{array}{l}\text { Age, } \\
\text { years }\end{array}$ & $74.9 \pm 7.5$ & $75.2 \pm 7.8$ & 0.99 & $\begin{array}{l}0.95- \\
1.04\end{array}$ & 0.75 & & & \\
\hline $\begin{array}{l}\text { Female, } \\
\text { n (\%) }\end{array}$ & $27(75)$ & $17(65)$ & 1.58 & $\begin{array}{l}0.74- \\
3.37\end{array}$ & 0.24 & & & \\
\hline $\begin{array}{l}\text { Body } \\
\text { mass } \\
\text { index }\end{array}$ & $22.5 \pm 4.5$ & $21.9 \pm 3.7$ & 1.03 & $\begin{array}{l}0.95- \\
1.12\end{array}$ & 0.44 & & & \\
\hline $\begin{array}{l}\text { AF } \\
\text { period, } \\
\text { months }\end{array}$ & $5(3,14)$ & $9(4,17)$ & 0.99 & $\begin{array}{l}0.96- \\
1.01\end{array}$ & 0.32 & & & \\
\hline $\begin{array}{l}\text { Heart } \\
\text { failure }\end{array}$ & $9(25)$ & $2(8)$ & 2.36 & $\begin{array}{l}1.10- \\
5.08\end{array}$ & 0.028 & \multirow[t]{2}{*}{1.79} & \multirow[t]{2}{*}{$\begin{array}{l}0.80- \\
4.04\end{array}$} & \multirow[t]{2}{*}{0.16} \\
\hline $\begin{array}{l}\mathrm{CHA}_{2} \mathrm{DS} \\
\text { score }\end{array}$ & VA. $\mathbf{A t} 1.3$ & $3.3 \pm 1.3$ & 1.14 & $\begin{array}{l}0.88- \\
1.47\end{array}$ & 0.33 & & & \\
\hline
\end{tabular}




\begin{tabular}{|c|c|c|c|c|c|c|c|c|}
\hline & Recurrence & Recurrence & Univariate & Univariate & Univariate & \multicolumn{3}{|c|}{ Multivariate Multivariate Multi } \\
\hline $\begin{array}{l}\text { Estimated } \\
\text { GFR, } \\
\mathrm{pg} / \mathrm{ml}\end{array}$ & $56 \pm 17$ & $49 \pm 19$ & 1.01 & $\begin{array}{l}0.994- \\
1.03\end{array}$ & 0.17 & & & \\
\hline $\begin{array}{l}\text { Left } \\
\text { atrial } \\
\text { diame- } \\
\text { ter, } \\
\text { mm }\end{array}$ & $40.6 \pm 5.4$ & $37.0 \pm 5.2$ & 1.07 & $\begin{array}{l}1.02- \\
1.14\end{array}$ & 0.013 & 1.06 & $\begin{array}{l}1.001- \\
1.13\end{array}$ & 0.047 \\
\hline $\begin{array}{l}\text { LVA } \\
\text { size, } \\
\mathrm{cm}^{2}\end{array}$ & $16.8 \pm 11.3$ & $14.1 \pm 9.6$ & 1.02 & $\begin{array}{l}0.99- \\
1.05\end{array}$ & 0.21 & & & \\
\hline $\begin{array}{l}\text { LVA } \\
\text { abla- } \\
\text { tion } \\
\text { (group } \\
\text { B) }\end{array}$ & $17(47)$ & $13(50)$ & 0.95 & $\begin{array}{l}0.49- \\
1.84\end{array}$ & 0.89 & 0.85 & $\begin{array}{l}0.44- \\
1.66\end{array}$ & 0.64 \\
\hline
\end{tabular}

Factors with $\mathrm{p}<0.05$ in the univariate analysis were incorporated in the multivariate analysis. ${ }^{*} \mathrm{AF}$ recurrence indicates recurrence of both atrial fibrillation and atrial tachycardia. HR, hazard ratio; CI, confidence interval, AF, atrial fibrillation; GFR, glomerular filtration rate; LVA, low-voltage area.

Table 4. Electrophysiological background of patients with and without biatrial tachycardia among patients who underwent LVA ablation (group B)

\begin{tabular}{llll}
\hline & Biatrial tachycardia & Biatrial tachycardia & $p$ \\
\hline & With $n=6$ & Without $n=24$ & \\
Left atrial volume, $\mathbf{c m}^{\mathbf{3}}$ & $90.3 \pm 12.7$ & $82.4 \pm 35.9$ & 0.72 \\
$\begin{array}{l}\text { Left atrial diameter, mm } \\
\text { Left atrial low-voltage area }\end{array}$ & $40.6 \pm 5.4$ & $39.7 \pm 5.9$ & 0.74 \\
Total, cm & & & \\
Anterior-septal region, cm & & & \\
Ablation lesions* & $23.9 \pm 18.3$ & $12.1 \pm 7.7$ & 0.020 \\
Roof line, $n(\%)$ & $12.1 \pm 6.9$ & $7.4 \pm 4.4$ & 0.049 \\
Bottom lines, $n(\%)$ & $5(83)$ & $12(50)$ & 0.20 \\
Anterior-septal mitral line, $n(\%)$ & $5(83)$ & $9(38)$ & 1.00 \\
Lateral mitral isthmus line, $n(\%)$ & $1(17)$ & $6(25)$ & 0.016 \\
Cavo-tricuspid isthmus line, $n(\%)$ & $5(83)$ & $3(13)$ & 1.00 \\
\hline
\end{tabular}

Ablation lesions at the timing of biatrial tachycardia induction for patients with biatrial tachycardia and final induction test for those without biatrial tachycardia.

Figure legends

Figure 1. Patient flow chart

Patients were followed up for $25(23,31)$ months. AF/AT recurrence after single ablation, repeat ablation, $\mathrm{AF} / \mathrm{AT}$ recurrence after multiple ablations, and AF/AT-free survival rates are shown. AF indicates atrial fibrillation; PVI, pulmonary vein isolation; LVA, low-voltage area; AT, atrial tachycardia

Figure 2. AF/AT-recurrence-free survival curves 
Kaplan-Meier curves for AF/AT-recurrence-free survival are shown. Patients without LVAs (group A) demonstrated excellent rhythm outcomes. In contrast, those with LVAs had a significantly lower AFrecurrence-free survival rate. Allocation to additional LVA ablation or not did not influence AF-recurrencefree survival rates. AF indicates atrial fibrillation; AT, atrial tachycardia.

\section{Figure 3. Transformation to persistent AF and late AF/AT recurrence}

Proportion of patients who developed AF/AT recurrence in persistent form in each group are compared (A). Patients with LVAs (group B and $\mathrm{C}$ ) demonstrated higher rates of transformation to persistent AF than those without (group A). Proportion of patients with late AF/AT recurrence defined as recurrence $>6$ months after the initial ablation are shown (B). Patients with LVAs experienced more late recurrence than those without. AF indicates atrial fibrillation; AT, atrial tachycardia.

Figure 4. Regular AT development during repeat ablation

During repeat ablation, a total of 31 spontaneous or pacing-induced ATs were mapped by a 3-dimentional mapping system. Prevalence of AT (left) and details of AT circuits (right) are shown. AT was more often observed in patients with LVA (Group B or C) than those without (group A). Patients who underwent LVA ablation (group B) had more frequent AT development than those did not (group C). All 6 biatrial tachycardias developed in patients with LVA ablation (group B). AT indicates atrial tachycardia.

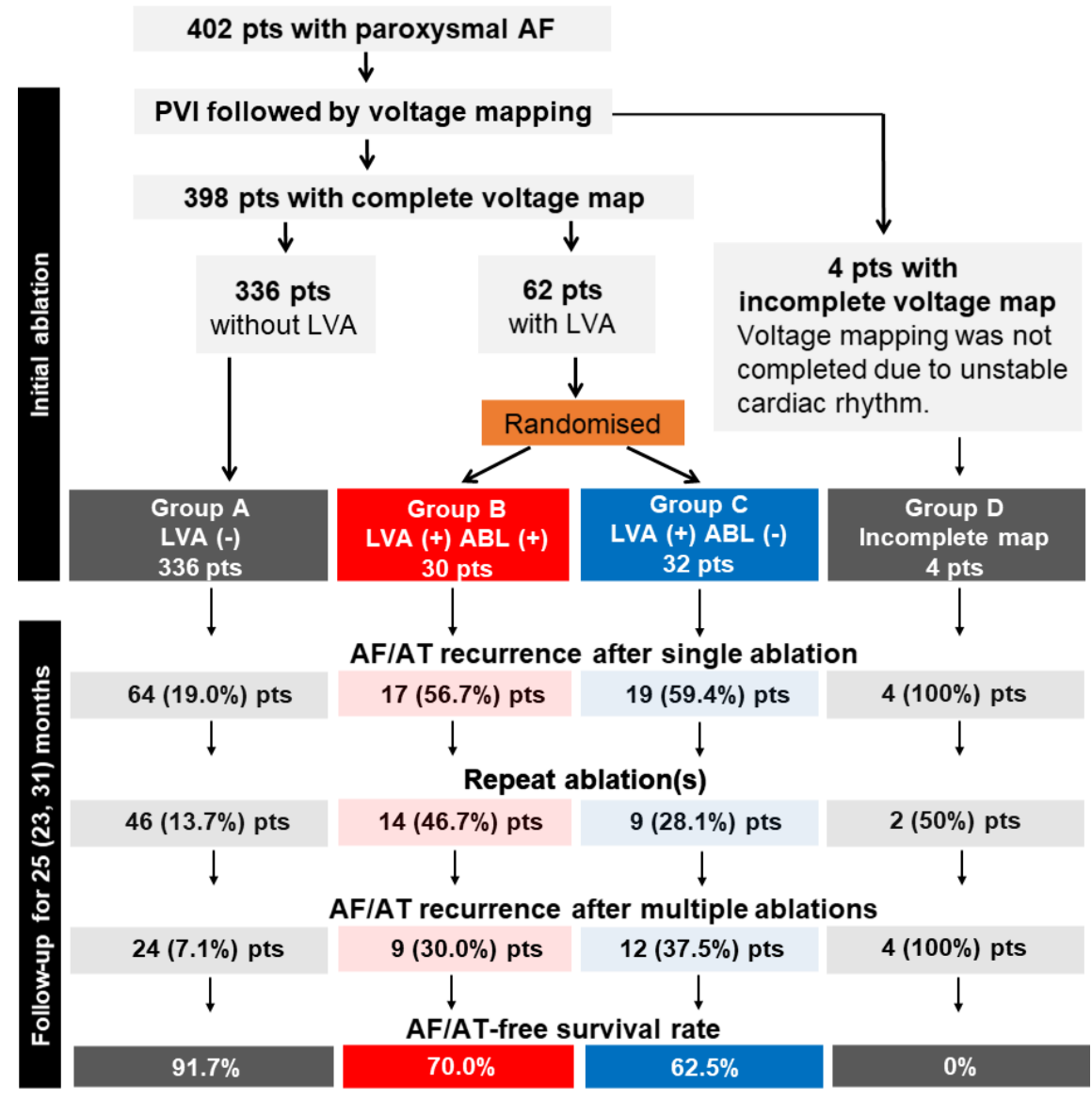




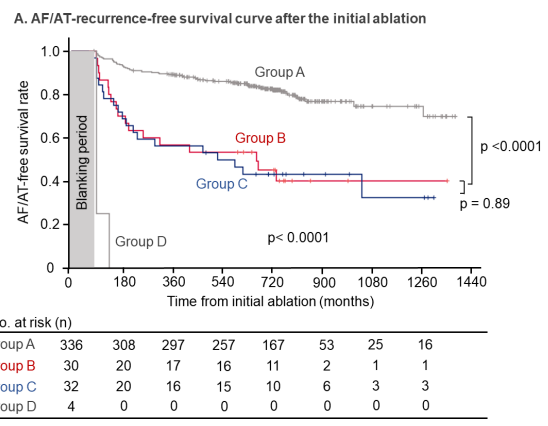

A. Transformation to persistent AF/AT

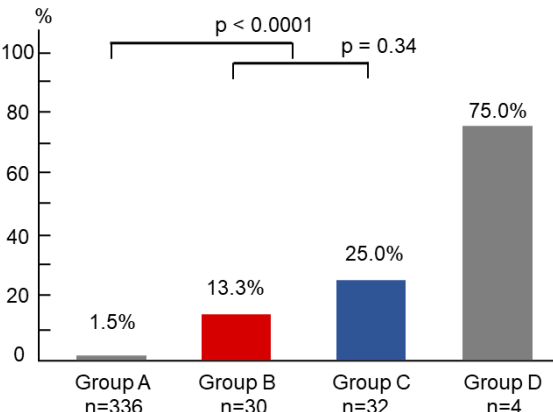

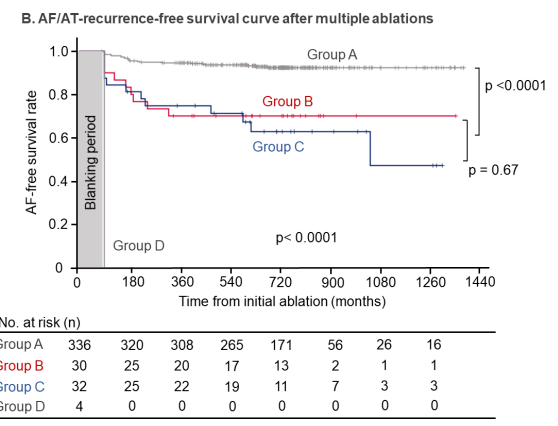

B. AF/AT recurrence at late phase (> 6 months)

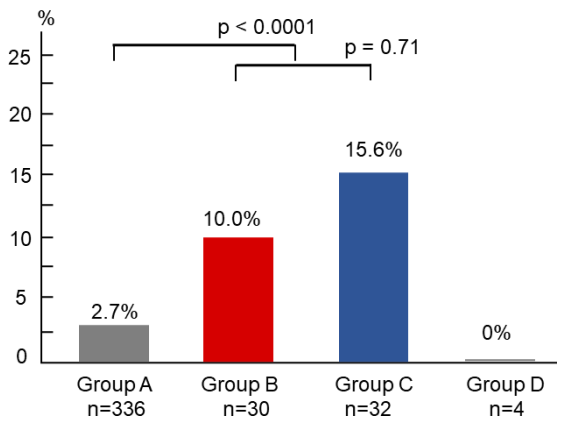

A. Prevalence of spontaneous or induced regular AT

B. AT circuits
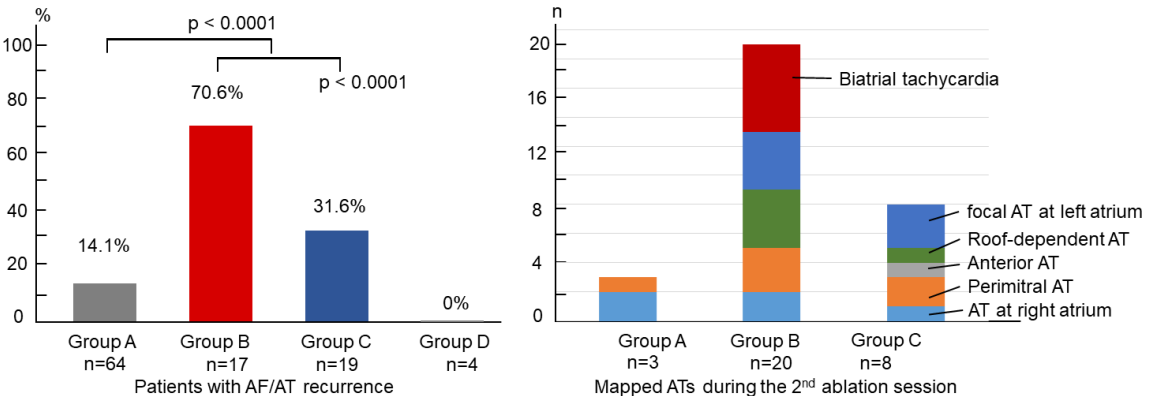

Patients with AF/AT recurrence 